Aka, A., Emuze, F., and Das, D. (2017). "Mapping Waste in the Structural Design Process in South African Projects." In: LC3 2017 Volume II - Proceedings of the 25th Annual Conference of the

International Group for Lean Construction (IGLC), Walsh, K., Sacks, R., Brilakis, I. (eds.), Heraklion, Crete, Greece pp. 475-482. DOI: https://doi.org/10.24928/2017/0053

\title{
MAPPING WASTE IN THE STRUCTURAL DESIGN PROCESS IN SOUTH AFRICAN PROJECTS
}

\author{
Adefemi Aka1, Fidelis Emuze2 and Dillip Das3
}

\begin{abstract}
Non-Value Adding Activities That Are Otherwise Called 'Waste' In The Lean Terms Have Continue To Hinder Efficient Project Delivery In The Construction Industry. As Such, The Types Of Waste And Their Impact Are Subject Of Many Studies. However, Much Have Not Been Done Regarding Waste In The Structural Design Process (Sdp). This Paper Reports On An On-Going Action Research Study On Waste In The Sdp. To Understand The Waste Types And Their Effects, The Lean Tool, Value Stream Mapping (Vsm), Has Been Deployed In The Doctoral Study. To Make Use Of The Tool For Sdp, A Purposively Selected Sample Of Consulting Structural Engineers, Practicing In Bloemfontein Were Interviewed In 2015. After That, A Vsm Depicting The Current State Of The Sdp And The Waste In The Process Was Compiled. The Vsm Tool Was Used To Analyze And Design The Flow Of Information. Major Waste Types Include Waiting Time, Excessive Motion, Excessive Production, And Excessive Inspection. The Eradication Of These Waste Influenced The Design Of A Proposed Future State Vsm Wherein All The Identified Problems Are Adequately Addressed. The Applicability And Usefulness Of The Vsm As It Enables Structural Designers To Perceive The Various Activities That Could Be Trimmed In Each Phase Of The Sdp Is Supported By The Results Of The Study, Although The Credibility Of The Future State Vsm Is Currently Being Examined By The Consulting Engineers.
\end{abstract}

Keywords: Construction, Design, Value Stream Mapping, Waste

\section{INTRODUCTION}

Non-value adding activities (NVAA) in projects are the unnecessary work done/activities and material loss in an undertaken. Such activities include waiting time, quality costs, lack of safety, rework, unnecessary transportation trips, long distances, improper management procedures, and poor constructability (Koskela 1992). The literature shows that most of the activities (waste) experienced in the construction phase (CP) of a project are due to the problems that are not discovered in the design phase (DP). To overcome this dilemma, Ko and Chung (2014) propose the use of lean concepts and a tool known as value stream mapping (VSM) in the DP of projects. It is essential to know that the idea of lean concepts (thinking) originates from production process, and can be viewed as a systemic method for the elimination of waste (Muda) within a

\footnotetext{
$1 \mathrm{PhD}$ Researcher, Unit for Lean Construction and Sustainability, Central University of Technology, Free State, Private Bag X20539, Bloemfontein, 9300, South Africa Tel: (051) 5073915 Fax: (051) 507 3254, E-mail: Aka Adefemi <aka.femi@futminna.edu.ng>

2 Associate Professor and Head, Department of Built Environment, Central University of Technology, Free State, Private Bag X20539, Bloemfontein, 9300, South Africa Tel: (051) 5073089 Fax: (051) 507 3254,E-mail: femuze@cut.ac.za

3 Senior Lecturer, Department of Civil Engineering, Central University of Technology, Free State, Private Bag X20539, Bloemfontein, 9300, South Africa Tel: (051) 5073647 Fax: (051) 507 3254, Email: ddas@cut.ac.za
} 
manufacturing process (Womack and Jones, 2003). Womack and Jones (2003) reveal that lean thinking are based on five main principles to guide management's actions toward success. These principles include: precisely specify value regarding a particular product; identify the value stream for each product; make value flow without interruptions; let the customers pull value from the producers, and pursue perfection.

In the lean construction literature, VSM has been described as a lean tool, and a particular type of flow chart that uses symbols known as 'language of Lean' to depict and improve the flow of inventory/information (Rother and Shook 2009). VSM is much more useful as a tool, and layout diagrams that produces a tally of non-values adding steps, lead time (LT), distance traveled, and the amount of inventory in a process (Rother and Shook 2009). According to Rother and Shook (1999), one biggest problem of VSM is the inability of an investigator to adequately understand how it future state should appear when applied to a process. This makes perfection in VSM system to be solely depends on the skill of the user. Based on this dilemma, Rother and Shook (1999) suggest that a VSM team should be led by someone that can see across the boundaries over which a product's value stream flows and make change happen in the boundaries.

Based on the opinions of Rother and Shook (1999; 2009) on VSM, attempts have been made by researchers to investigate how the tool can be espoused for waste identification in projects (Alvarez et al. 2009; Goransson, 2012). However, the findings in the reviewed literature shows that the DP of projects is not adequately covered. Ko and Chung (2014) have adopted the strategy for waste identification and reduction in the construction design process (CDP), specifically in the architectural process (AP). Ko and Chung (2014) in their study show that AP is by nature a multidisciplinary effort that requires the consideration of many aspects, such as structural composition, water drainage, and many more. Premised on this contention, it can be assumed that the analytical frameworks devised by the researchers for waste elimination in the CDP may be generalized to other aspects of project design. However, the desire of the structural design team (SDT) to produce a structure that is capable of resisting all imposed load without failure during its expected lifetime necessitates that structural design be explicitly distinguished from the AP. Hence, further studies are required to expand on the existing theories and knowledge in other aspects of the CDP such as the structural design process (SDP).

\section{METHODOLOGY}

This research aims to identify the various waste that are significant to the SDP in the South African context. To achieve this goal, an action research design explained by Stringer (2014) was conducted in 2015. The study was carried out with groups of consulting engineers in five different firms located in Bloemfontein. The selection of the companies was based on purposive sampling techniques (Ritchie and Lewis 2003). That is, companies that have designers with extensive work experience in the SDP, and are affiliated with Consulting Engineers South Africa (CESA), were chosen. To be precise, five designers (a combination of both senior and junior engineers) and a technologist that have been working together as a team for not less than five years across the various design projects (residential, commercial and industrial) were selected in each firm for data collection. It is essential to note that focus interviews served as the main technique for data collection in the study in all the five firms. The focus interviews were used to understand the current flow of activities in the inception design phase (IDP), the predesign phase (PDP), and the detailed design phase (DDP) of the SDP. After that, VSM 
proposed by Rother and Shook (2009) was depicted on the flow of the activities by the researchers to identify the various NVAA in the practice.

After the depiction of the VSM exercise, another focus interviews were conducted in each firm. The essence of the second round of the interviews was to enable the researcher and the participants in all the groups to observe clearly the various waste in each phase of the SDP and to propose for different strategies that can be adopted to eliminate the identified waste. For consistency, the focus interviews in each step of the study (diagnosing/action planning) were conducted thrice in each firm. Each focus interview in all the firms was between 60 to 80 minutes in duration. All the focus interviews discussions in each firm were recorded and transcribed (Arksey and Knight 1999). After transcription, the resultant information was analyzed using content analysis method (Krippendorff 2012). The resulting information from the interpreted data (themes) were validated using follow-up interviews, which were conducted by the researchers with the head (the chief engineer) of each group of respondents in all the studied firms.

\section{RESULTANT DATA AND DISCUSSION}

\section{Non-value Adding Activities in Structural Design Process}

In the study conducted, it was discovered that the current flow of activities in the IDP, the PDP and the DDP of the SDP appeared impeccable to the SDT but after the adoption of VSM, the teams in all the groups realized that several NVAA (waste) such as excessive meetings, delay to establish contract agreement between the client and the SDT, several soil test, waiting for the site report, poor site report, ambiguities in the architectural drawings, design variations/modifications, several structural calculations, wrong structural computations, excessive vigilance, and several paperwork are prevalent in the practice. These waste are clearly marked out with a VSM symbol known as kaizen burst (Figures 1 and 2). For adequate understanding, details of the waste in the PDP and the DDP are alphabetically represented in Table 1 . While Table 2 presents the details of the various indispensable activities that constitute the waste in each phase. For the same reason, Table 3 provides the VSM predefined icons that are used in the two figures.

It is pertinent to know that after the depiction of the VSM tool to the various indispensable activities in each phase of the SDP, the researchers and the study participants discovered that some of the activities also required to be ameliorated. These activities are also clearly marked out with the kaizen burst in the two figures. It should be noted that all the LT and the actual process time (PT) shown in the two figures in this study were obtained from the participants in all the groups based on their experiences in the previous executed projects (residential, commercial and industrial). Hence, the LT and PT are premised to the design of any highly challenging commercial or industrial buildings such as high-rise or multi-storey structures.

Table 1: Waste in the structural design process

\begin{tabular}{l}
\hline PDP \\
Excessive meetings among the project actors (A); several
\end{tabular}




\begin{tabular}{|c|c|}
\hline $\begin{array}{l}\text { disagreements between the architect and the SDP on the } \\
\text { critical aspects of the project (D); waiting for the modified } \\
\text { drawings (Architectural drawings) (E); delay to establish and } \\
\text { incorporate the necessary building requirements/codes into } \\
\text { the project (F); several design computations }(\mathrm{G}) \text {; unnecessary } \\
\text { mistakes/errors during the computations (H); several } \\
\text { corrections by the senior designers during the computations } \\
\text { exercise (I); further clarify areas that are needed to be } \\
\text { corrected or improved (paperwork) (J), and Waiting for } \\
\text { preliminary design documents (K) }\end{array}$ & $\begin{array}{l}\text { PDP (D); delay to incorporate the observed } \\
\text { comments into the project as earlier scheduled (E); } \\
\text { delay to include other consultants' requirements } \\
\text { into the project as earlier scheduled (F); several } \\
\text { printing of the draft drawings }(\mathrm{G}) \text {; waiting for the } \\
\text { approval of the final drawings }(\mathrm{H}) \text {; unnecessary } \\
\text { copies of the final designs (I); delay in the } \\
\text { production of the construction drawings }(\mathrm{J}) \text {, and } \\
\text { slow to establish detailed design documents (K) }\end{array}$ \\
\hline
\end{tabular}

Table 2: Indispensable activities in the structural design process

\begin{tabular}{|c|c|}
\hline PDP & DDP \\
\hline $\begin{array}{l}\text { Attend the design and the consultant meetings (PDP-1); } \\
\text { review the architectural drawings in details (PDP-2); } \\
\text { modification of the architectural drawings (PDP-3); } \\
\text { establish regulatory authorities requirements/necessary } \\
\text { building codes and incorporate them into the drawings } \\
\text { (PDP-4); establish structural predesign criteria (PDP-5); } \\
\text { refine the predesign criteria to ensure conformance with } \\
\text { all regulatory requirements } \\
\text { /building codes and consents (PDP-6); compute the } \\
\text { general layout, preliminary sizing and stability of the } \\
\text { proposed structural elements of the project (PDP-7); } \\
\text { prepare the preliminary process designs and related } \\
\text { documents suitable for costing (PDP-8); review the } \\
\text { overall work for approval to the next phase (PDP-9); } \\
\text { establish initial design documents (PDP-10). }\end{array}$ & $\begin{array}{l}\text { Attend consultants meetings (DDP-1); review the } \\
\text { predesign documentation plans with other consultants } \\
\text { that may be involved (DDP-2); select the most suitable } \\
\text { proportions, dimensions and connections of structural } \\
\text { elements computed in the predesign phase (DDP-3); } \\
\text { incorporate the necessary corrections, comments and } \\
\text { observations in the predesign phase into the work } \\
\text { (DDP-4); incorporate other consultants designs and } \\
\text { requirements into the work (if any) (DDP-5); prepare } \\
\text { the design development drawings including draft } \\
\text { technical details/specifications (DDP-6); review of the } \\
\text { developed final drawings (DDP-7); approve the final } \\
\text { drawings (DDP-8); produce the construction drawings } \\
\text { (DDP-9), and establish the detailed design documents } \\
\text { (DDP-10). }\end{array}$ \\
\hline
\end{tabular}

Table 3: The predefined icons for the value stream mapping process

Description
customer/Supplier Icon (C/SI): represents the Supplier when in the upper left,
Dedicated Process Flow Icon (DPFI): a process, operation, machine or department,
through which material flows. It represents one department with a continuous,
internal fixed flow



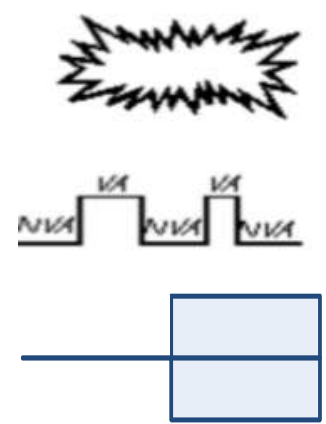

(Adapted from Rother and Shook, 2009)

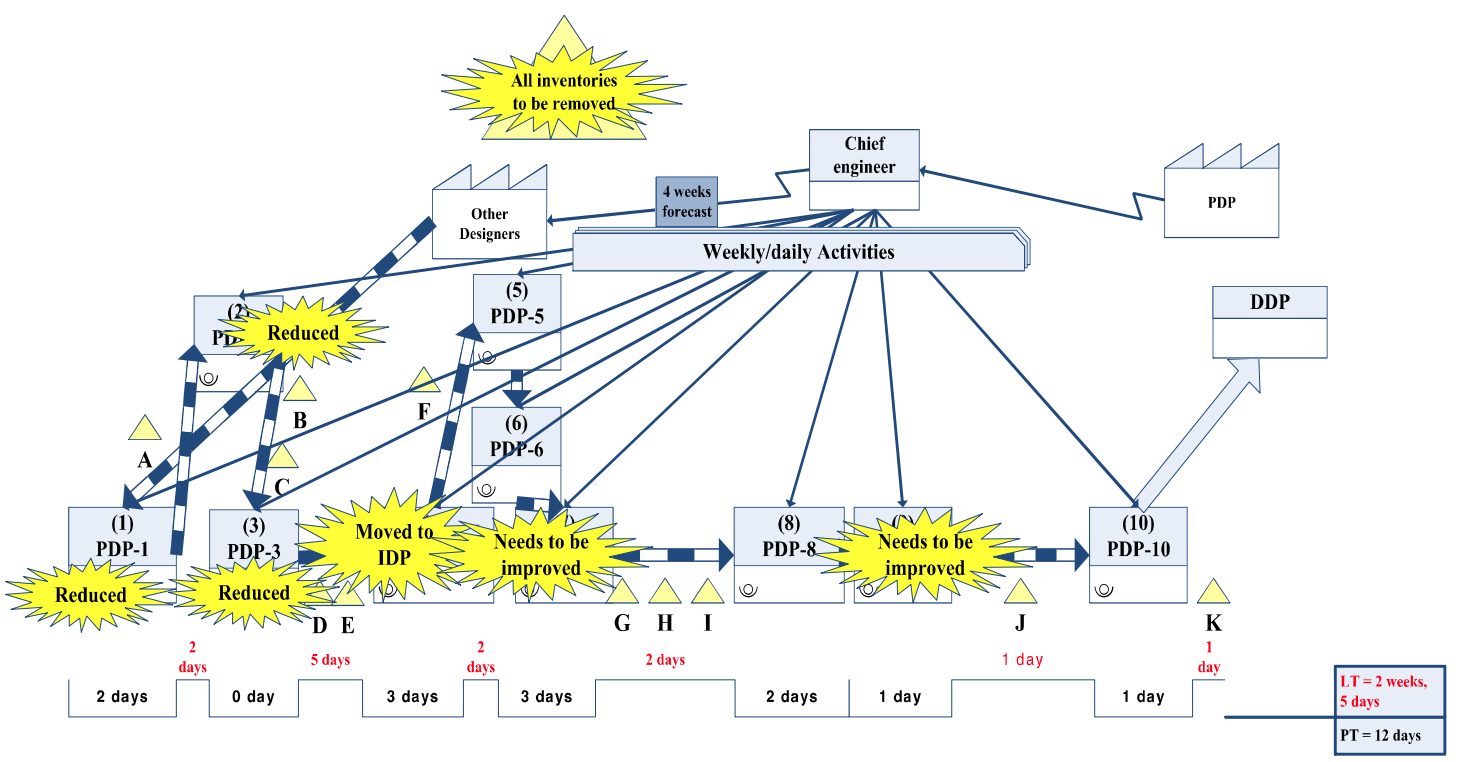

Figure 1: The current state value stream mapping in the predesign process

\section{STRATEGIES THAT CAN BE ADOPTED TO REDUCE THE IDENTIFIED WASTE}

Several strategies that can be adopted to reduce the identified waste in the SDP were proposed by the participants in the study. Among these strategies is adequate involvement of the SDT in the AP. The participants emphasized that the process will enable the two parties (the architect and the SDT) to detect and rectify most of the problems encountered in the SDP, and come up with an appropriate architectural drawings (AAD). Hence, activities such as several meetings and disagreements between the architect and the SDT, delay to establish contract agreement between the client and the SDT, several review of the architectural drawings, modifications of architectural drawings, and excessive waiting during the amendment exercise can be eliminated in the process. This is in agreement with the views of Forbes and Ahmed (2011), Eastman et al. (2011) regarding the application of information and communication technology platforms for waste identification and reduction in the design and the construction phases of projects. 


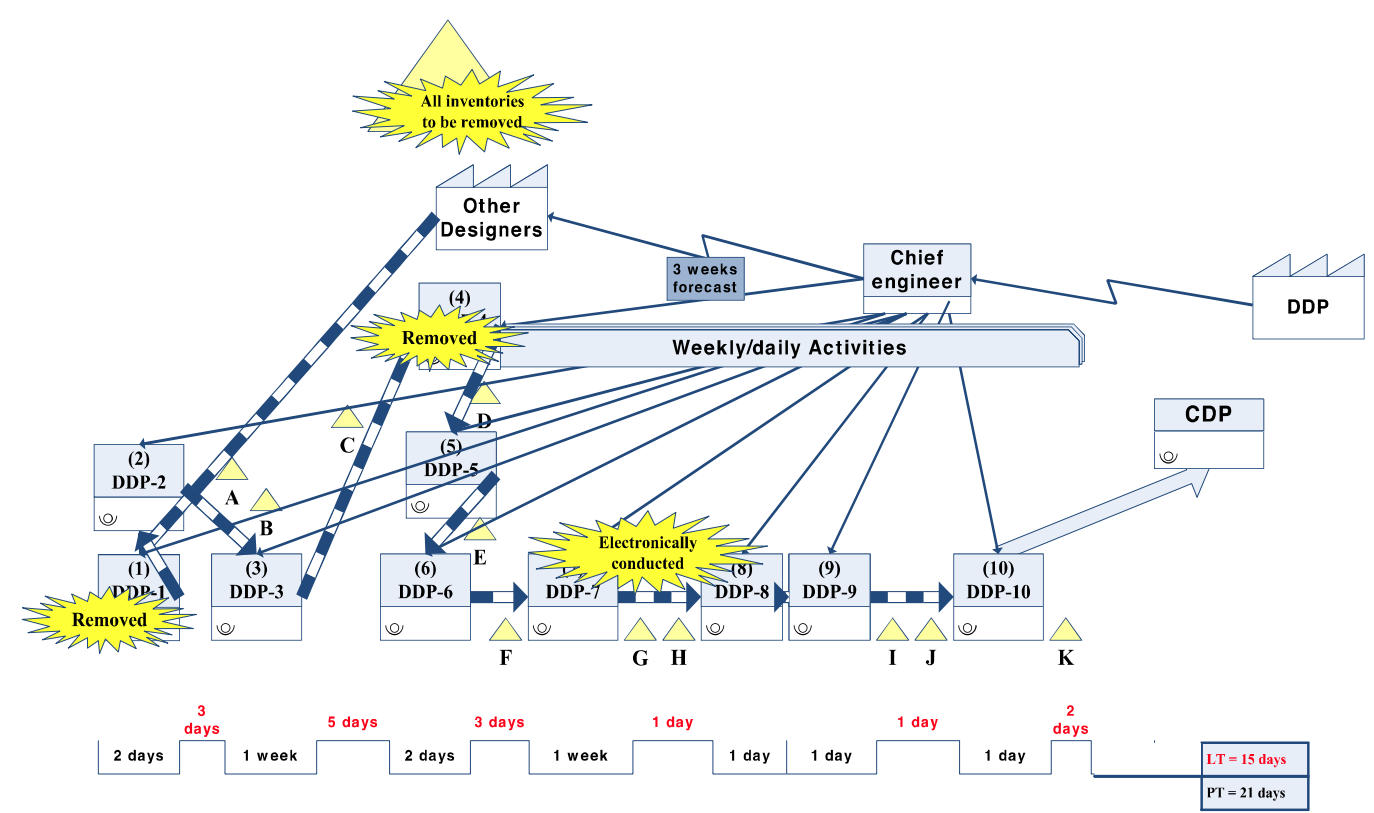

Figure 2: The current state value stream mapping in the detailed design process.

The participants further stated that the strategy will also enable the structural designers to perform some of the IDP and the PDP activities during the AP. This means that requisite activities such as attend project initiation meetings so as to implement contract agreement between the client and the designers, review of the architectural drawings, defining the services/scope of the project, give favourable advice in term of the project life cycle costs, schedule and inspect on the necessary land topographical survey/soil tests, and oversee the compilation process of site reports in the current IDP and PDP can be conducted earlier. While activities such as establish the necessary regulatory requirements/building codes and incorporate them into the project in the PDP (PDP-4) can also be performed during the AP process. Therefore, the proposed concept will not only lead to AAD, but will also avail the SDT the opportunity to reduce several waste in the IDP and the PDP of the SDP. Such waste includes excessive meetings between the architect and the SDT, waiting for site report and all other forms of delays experienced in the two phases which includes lateness to define the services/the scope of the project, give favourable advice in term of the project life cycle costs, and delay to establish the inception and the predesign documents.

Some of the participants in all the groups further stressed that structural designers should ensure that vague assumptions are reasonable and minimal during the geotechnical investigation of the proposed site, and experienced designers such as senior engineers should be adequately involved in the computation aspect of the SDP, rather than to assume responsibility for supervisions only. The participants emphasized that the above-stated opinions will enable the SDT to timely detect and rectify most of the structural computation errors/wrong computations that are being experienced in the PDP, which will consequently reduce the rate of mistakes in the DDP of the SDP. This means that waste such as several corrections/redesign, several supervisions, excessive paperwork, delay to prepare the design development drawings/specifications, lateness 
in the completion of tasks as scheduled, waiting for the approval of final drawings from the senior/the chief engineer of the firm, delay to produce the construction drawings, and establish the detailed design documents, in the DDP of the SDP can be reduced or eliminated.

Based on the opinions of the participants in all the groups, the actuality/practicality of the expected (proposed) future state VSM in the IDP, the PDP and the DDP are currently being examined by the consulting engineers in the study context.

\section{CONCLUSIONS}

Based on the study conducted, it can be concluded that NVAA or waste exist in every phase of the SDP. The NVAA can be identified through the application of a lean tool known as VSM. The waste that can be identified in the PDP of the SDP through the application of the tool are several disagreements between the architect and the SDT; several unclear information in the architectural drawings; excessive meetings between the architect and the SDT; design modifications in architectural drawings during SDP; excessive waiting due to the modification of the architectural drawings; incorrect information in structural computations/wrong computations or computation errors; excessive printing of paperwork; excessive supervision of design activities by the chief engineer, and delay to establish the preliminary design documents by the project actors. These discoveries are also consistent with the findings of Mossman (2009) and Nagapan et al. (2012) regarding some of the waste in projects.

While in the DDP of the SDP, typical examples of the waste that can be identified with the adoption of VSM are design corrections/redesign; excessive printing of draft/paperwork; lateness in the completion of a task as scheduled; waiting for the approval of final drawings from the senior/the chief engineer of the firm; delay to select the suitable structural elements computed in the PDP; delay to incorporate other consulting engineers requirements into the project; delay to prepare the design development drawings/specifications, delay to produce the construction drawings/establish the detailed design documents, and several copies of the final drawings. These results are similar to the findings of Simms (2007) and Gatlin (2013) concerning some of the waste in engineering design. This study recommends that VSM and the five lean principles should be adopted by the SDT for waste identification and reduction during SDP. However, it has been observed in the literature that the proficiency of the future state VSM depends on the skill of the operators. Therefore, for proficient and well-organized future state VSM in the IDP, the PDP and the DDP, a more compressive VSM software that is independent of the skill or ability of the operators should be investigated or developed by future researchers.

\section{REFERENCES}

Alvarez, R., Calvo, R., Pena, M. and Domingo, R., (2009). Redesigning an assembly line through lean manufacturing tools. International Journal of Advanced Manufacturing Technology, 43, pp. 949-958.

Azhar, S.M.H. and Sketo, B., (2008). Building information modeling: Benefits, risks and challenges. In: Proceedings of the 44th ASC National Conference. Auburn: Alabama.

Eastman, C.M., Teicholz, P., Sacks, R., and Liston, K., (2008). BIM handbook: A guide to building information modelling for owners, managers, architects, engineers, 
contractors, and fabricators. John Wiley and Sons, Hoboken, NJ. Pp. 21-23, 152160.

Forbes, L.H., and Ahmed, S.M., (2011). Modern construction: Lean project deliver and integrated practices. Boca Raton, Florida, USA, CRC Press, Taylor and Francis Groups.

Gatlin F., (2013). Identifying and managing design and construction defects. Navigant Consulting Inc. Pp. 1-11.

Goransson, I.F.G. (2012). Value stream mapping in product development: Adapting value stream mapping at Ascom Wireless Solutions. Master Thesis, Department of Product and Production Development, Chalmers University of Technology Gothenburg, Sweden.

Krippendorff, K., (2012). Content analysis: an introduction to its methodology. London: Sage.

Ko, C.H. and Chung, N.F., (2014). Lean design process. Journal of Construction Engineering and Management, 4(3), pp. 464-468.

Koskela, L.J., (1992). Application of the new production philosophy to construction. Technical Report No.72. Stanford, CA: Centre for Integrated Facility Engineering, Stanford University.

McNamara, C., (2009). General guidelines for conducting research interviews. Retrieved January 11, 2010, from http://managementhelp.org/evaluatn/intrview.htm

Mossman, A., (2009). 'Why isn't the UK construction industry going lean with gusto?' Lean Construction Journal, 5(1), pp. 24-36.

Nagapan, S, Rahman, I.A, Asmi, A., Memon, A.H. and Zin, R.M., (2012). Identifying causes of construction waste: Case of Central Region of Peninsula Malaysia. International Journal of Integrated Engineering, 4(2), pp. 22-28.

Ritchie, J., Lewis, J. and Elam, G., (2003). Designing and selecting samples. In: Ritchie, J. and Lewis, J., 2003 (edited). Qualitative research practice: A guide for social science students and researchers. London, CA: Sage.

Rother, M. and Shook, J., 1999. Learning to See: Value Stream Mapping to Add Value and Eliminate Muda. Brookline, MA: The Lean Enterprise Institute.

Rother, M. and Shook, J., (2009). Learning to see: Value stream mapping to create value and eliminate Muda. Forwarded by Womack, J. and Jones, D. A. Lean tool kit method and workbook.

Simms, M., (2007). The seven wastes in engineering design: a new look at lean manufacturing. Brea, CA: KETIV. Pp. 1-5.

Stringer, E.T., (2014). Action research. 4th edition, Thousand Oaks, CA: Sage. 